\title{
Sufficiency Economy: Demission of Social Capital Development to the Pace of Change in the $21^{\text {st }}$ Century of Thailand
}

\author{
Paitoon Pimdee $^{1, *}$, Pornchai Jedaman ${ }^{2}$, Kollawat Wang-Saorad ${ }^{3}$, Nittayaporn Kinboon ${ }^{4}$ \\ ${ }^{1}$ Faculty of Industrial Education, King Mongkut's Institute of Technology Ladkrabang, Thailand \\ ${ }^{2}$ Rajabhat Maha Sarakham University, Thailand \\ ${ }^{3}$ Huaiphungphittaya School, Rajabhat Karasin University, Thailand \\ ${ }^{4}$ Phuwiengwittayakom School, Khon Kaen Province, Thailand
}

Copyright $(2017$ by authors, all rights reserved. Authors agree that this article remains permanently open access under the terms of the Creative Commons Attribution License 4.0 International License

\begin{abstract}
Modernization brings a major shift into the development process in the society of Thailand. The phenomenon started from foreign powers authority, either in the form of knowledge or assistance came to the domination. Determining discourse to generate new meaning on the Sufficiency Economy is demanded for fully responding to modernization era. Does the modern development in globalization cause the impacts? This research aims to study the respondents' ideas towards Sufficiency Economy: demission of social capital development to pace of change in the $21^{\text {st }}$ Century of Thailand. This was a qualitative research using the semi-structure questionnaire plus triangular check from the documentary and participatory action learning (PAL) with the community leadership. The respondents were 240 persons from purposive sampling in three provinces of Thailand. The qualitative data were analyzed by using three main stages: data reduction, data organization, and data interpretation to conclusion. The results consisted of five themes: I) Minds Dimension including the mentally strong awareness and realization that good, the independence of thought and action, creativity generosity and compromise, II) Social and Economic Dimension including the buddy, to link a strong network, to have a careful planning in managing existing assets, to have a backup plan in immune system of the risks and alternatives, the value and development, III) Technology Dimension including the selection of what suits your needs, knowing to improve the environment and the reality, IV) Cultural Dimension including an intellectual development potential and the uniqueness, and V) Resources and Environment Dimension including the development and use to the appropriate values.
\end{abstract}

Keywords Sufficiency Economy, Social Capital Development, the $21^{\text {st }}$ Century, Thailand

\section{Introduction}

The social change of Thailand, when looking back to the past, traditional society is a society where life is simple, there is a production-based economy to sustain consumption for household and in the community not for the exchange of the raw materials for sustenance, comes from the natural surroundings. These factors where Society and Community bind an affinity and awareness to express in the beliefs and rituals maintain balance. ${ }^{[1]}$ Moreover, the relationships of kinship and blood relations correspond to the use of shared resources, including dependence on various aspects.

These characteristics Society in Thailand peaceful existence, self-reliant and self-sufficient to conventionally to inherit the identity continued uninterrupted ever since. Social changes to be taking place on the social development of Thailand into the process of the Westerns modernization. Such phenomena starting on power and privilege in the form of knowledge, assistance came to dominate, act. Defines discourse to create a new definition of what is the opposite of Sufficiency Economy was development and under development. Cause demand to develop innovative ways of the actions aimed at improving the economic and the social structural reform, whether it is the political, educational, beliefs in accordance with the Westernization. ${ }^{[2]}$

Reason for such as a result, the goals and guidelines developed in the past. Aims to make of Thailand modern society to according of the Western society, whether it is to focusing on economic development, the nature of the capitalist mode of production by promoting an expansion of the industry and trade, to using advanced technologies simultaneously with political reforms, education, for the social structure to the specific duties of effective to the resulting expertise, can add of performance to a higher and contributing to the development of modernity. Result of the positive developments including of increase in the rate of 
economic growth, material progress structures, advanced communication system or expanding the amount and distribution thoroughly studied. But these positive results it continues to spread of the peoples in rural and disadvantaged minority, most of which are concentrated in the capital and the provinces. ${ }^{[3]}$

While the result was negative, the expansion of the industry for trade and export, and the expansion of government into the countryside to have contributed to the weakness in many rural areas were as; the dependence of the market from the authority or middlemen, the system ties of kinship and confederation tradition in order to managing of an available resources to break down, the wisdom gained from to being forgotten, lost. Such as, the change would make lifestyle, the vision, belief system and values of the societies and communities to variations of the original. ${ }^{[5]}$ Crisis caused by weakness in the community including socials and economical of the impacts to proves and confirms this phenomenon as well. The result, raises questions and doubts of development through Westernization, it is believed that before. Is the right and proper to the contexts of the next Thailand or not. ${ }^{[4]}$ Thus was born the concept of dispute related to the development in modern theory including dependency theory, sustainable development, cultural community theory, that to seeming to answers of developing a robust future. This result a major shift occurred when the society of Thailand into development process towards modernization. The phenomenon started when foreign powers authority, either in the form of knowledge, assistance came to the dominate, determining discourse to create new meaning on the opposite of Sufficiency Economy including the development, under development to born demand of the modernization. Is the globalization of development towards modernization cause of the impact continues.

Sufficiency economy is the philosophy solicited by King Bhumibol since the 1990 to guide lives and welfare of all Thais. The sufficiency economy is understood most usefully as a primer to help Thais, especially those with modest assets, to make their way among the largely unfamiliar signposts of globalized markets. ${ }^{[8]}$ It is based on the way and the practice of self-dependence, self-sufficient, modest and realistic including the knowledge and global literacy to use to the development of stable and sustainable. The figure consists of three main features issue to moderation, reasonableness, self-immunity, and located on two conditions as; knowledge and morris. ${ }^{[3]}$ Danny $[2009]^{[8]}$ stated that the Sufficiency Economy Philosophy (SEP) supports sustainable development of Thailand and is aligned with the United Nations Development Program. The SEP suggests the matching between fundamental economic and political institutions, on the one hand, and widely held norms as Buddhist, on another. As such, value changes and building norms are mandated to the successful implementation of SEP encompassed with economic and political thoughts. The origins of sufficiency economy and religious economics are close together.

Darren $\left[2011^{[10]}\right.$ studied the origin of Thailand's sufficiency economy and compared it with other systems of religious economics. He stated that the origins and principles of sufficiency economy shared some commons with the models of Buddhist, Islamic, and Gandhian economics. For example, sufficiency economy, following Buddhist teachings, ultimately seeks not wealth production, but happiness. The sufficiency economy model tries to balance many of the polarities and extremes of the contemporary world. It seeks to avoid consumerism and to value spiritual happiness, while also ensuring successful material production and growth. Sufficiency economy is not as an opposition to globalization or capitalism, but as an approach by which individuals or countries can successfully enter into globalization while protecting themselves from its dangers and risks. Sufficiency economy and Islamic finance are similar in that both are pro-capitalist systems that propose tempering capitalism with religious principles and restrictions. Sufficiency economy and Islamic finance also have major institutional support in terms of having been adopted as the policy of nations or large economic institutions and companies.

The applications of sufficiency economy are diverse. Amalia $[2012]\left[{ }^{11]}\right.$ discussed the use of Sufficiency Economy through many Royal Projects to moralize the environmental behavior of hill tribes in Nan province, Northern Thailand. This study suggested that the recently increased trend of staging new projects for sustainable agro-forestry management in a 'red' area as Nan does not only aim at improving the conditions of hill tribes and of the environment, but simultaneously increases the political influence of the conservative forces over this 'ungovernable' territory in times of political crisis. In this scenario, the Royal Projects in Nan not only offers new solutions to natural resources management in areas afflicted by shifting agriculture but also works as an inclusive and soft strategy of conservative rule.

Other two major examples are also presented here. Curry and Sura $[2007]^{[7]}$ presented one distinct example of sufficiency economy that is the "One Tambon, One Product Program" (OTOP) project, which local communities form private sector enterprises producing and marketing products made from local resources and made by local workers whose skills are improved with assistance that increases their technical and marketing attributes. They mentioned that the design and implementation of OTOP project are consistent with the United Nations Economic and Social Commission for Asia and the Pacific (UNESCAP) approach. The goals of OTOP are reducing the need for public funding, limiting the fiscal and programmatic involvement except to provide technical, managerial, administrative and informational assistance in the processes of producing, financing and marketing products. OTOP is a useful example of a program that provides a linkage among private and public sector development initiatives. Sufficiency economy provides the 
foundation for OTOP and they combine to make operational the integrative-thematic human resource development (HRD) approach put forth by UNESCAP. Another example is the use of sufficiency economy to design a spatial decision support system for local government decision making. Boondao $[2011]^{[9]}$ developed the spatial decision support system based on the principles of the Self-sufficiency Economy. She then implemented the created spatial decision support system for local government decision making four provinces i.e. Ubon Ratchathani, Yasothorn, Sisaket, and Amnat Charoen. The system was implemented using UMN MapServer and PHP programming. The study involved evaluation of information needed, development of the spatial decision support system, and evaluation of strategic planning for the areas. The results of the testing showed that the users' satisfaction with the system was at a good level. It is anticipated that local governments' use of the system will allow formulation of strategic plans to develop the provinces in relation to identified issues and prioritize areas for preparation of development, resources allocation and public service planning according to the principles of Self-sufficiency Economy.

In Thailand the concept of social capital is not new, but existed previously. Only the direction and development policies have driven the expansion of economic development focusing of physical capital and financial capital, regardless of the development of social capital. In addition, the results from the development has brought people into Thailand to careless society of competition and conflict. ${ }^{[6]}$ The joint activities of civic communities is creating and maintaining social relationships to pose together as a network to help each other and survive even in the crises, these movements It is known as the structure of social glue to organizations can create, relationships and norms of causing both quantity and quality. The research questions for this study are: What are the respondents' ideas towards the sufficiency economy: demission of social capital development to pace of change in the $21^{\text {st }}$ Century of Thailand in the element? And Why and How?

\subsection{Objective Study}

This study aims to study the sufficiency economy in the respondent's ideas towards the sufficiency economy: demission of social capital development to pace of change in the $21^{\text {st }}$ Century of Thailand.

\section{Methodology}

\subsection{Type of Research}

This study is a qualitative research including a participatory action learning aimed to gather an in-depth understanding of the sufficiency economy in the demission of social capital development to pace of change in the $21^{\text {st }}$ Century of Thailand. The sufficiency economy is based on the way and practice of self-dependence, self-sufficient, modest and realistic including the knowledge and global literacy use of the development to stable and sustainable of three main features issue to moderation, reasonableness, self-immunity, and located on two conditions as; knowledge and morris, behavior and the reasons that govern such behavior. The discipline investigates the "why" and "how" of decision making.

\subsection{Sampling Method}

The respondents were purposive sampling. The total number of respondents was 240 coming from the community leadership in three provinces of Thailand.

\subsection{Data Collection}

The respondents were asked to respond to the semi-structured questionnaire, which required the information about the sufficiency economy of main features issue to moderation, reasonableness, self-immunity, include located on conditions as; Knowledge and Morris. Statements that are perceived to be factors that the influence of social capital to development of the element as; I. Philosophy of sufficiency economy base, II. Dimensional sufficiency economy to development of social capital, and III. Dynamic social capital with sustainable development. In addition, the documentary and participatory action learning of the interviews were conducted to obtain more in-depth data.

\subsection{Data Analysis}

The data analysis was descriptive statistics. The qualitative data was analyzed by triangular check using three stages: data reduction, data organization, data interpretation to conclusion.

\section{Major Findings}

Table 1. Main thought and Consideration of Sufficiency Economy in the Quality and Potential of Social Capital

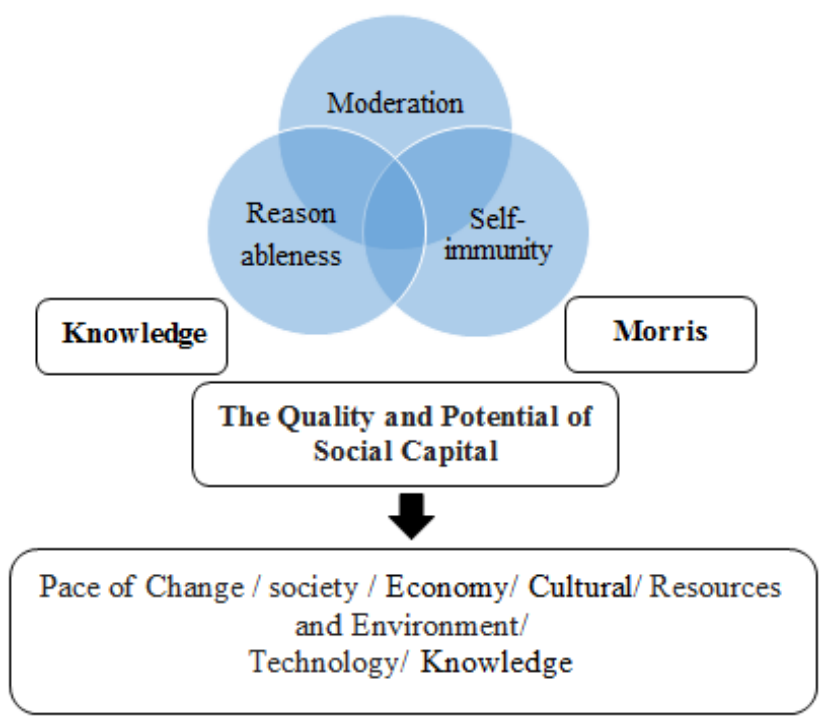


The results yield three themes of Sufficiency Economy in the demission of social capital development to pace of change in the $21^{\text {st }}$ Century of Thailand, which consists of moderation include three mains and located on two conditions.

\section{Philosophy of Sufficiency Economy Base}

Sufficiency Economy to just not the technique, but has a much broader meaning because of the ideology and worldview, relationships and values that meet or match that represents a real economic sufficiency, implied or otherwise known as cultural that to following:

Moderation three Mains: i) Moderation, the fit is not too much, not too little, not too extreme. Must be based on need, not hurting yourself and others to build a strong self, reduce dependency on other, ii) Reasonableness, the decision must be based on reasonable grounds and associated factors, regardless of the consequences carefully, honest and unbiased, iii) Self-immunity, the prepare for the impact and the change that to the located in a precaution.

Located two conditions: i) Knowledge, the knowledge about science in all-round way on order to put that knowledge to use coherent planning and practice, ii) Morris: the awareness of the virtues to honest, have patience, perseverance and wisdom in life, there leniency unity. A major focus on development a sustainable component as follows:

a) Understand what needs to be changed naturally: the environment and timing.

b) Creating readiness for change: use to thinking and seeing the dynamics of change, analysis of causes and factors, to prepare for the changes that will occur.

c) Creating a balance Stability and sustainable: use to analysis of the results occurred in both the short and long terms, the aim of public interest in the context of community organizations to make a balance and Sustainable.

d) Having the fit and proper: to knows of self, networking groups and expand the range of activities from to establishing cooperation in all sectors to benefit, and development in the quality of life, efficiently.

e) Knowledge and morality: based on good governance, the consciousness and learning to seek knowledge continuously.

f) Self-reliance, interdependence and collective responsibility: knowing how to build relationships and partnerships, help share, the cheryl lived were to the values for the sake of the common good and know the responsibility is important.

\section{Dimensional Sufficiency Economy to Development of Social Capital}

Sufficiency Economy of a sequel to the lifestyle of the people and human needs: On the whole, there are two levels as; i) Physical Needs: was the basic needs of life, so that life can exist according to individuality, considering the Buddhist religion is the demand for the exists and a factor of four to as; foods, clothes, housing and medicine. Is the limited quality of life demanded? ii) Mental Image Needs: was society needs mental way in addition to the physical of the situation; have a craving, and the splendor passion don't want to be there are such as needs love and joy that their expectations, the prestigious honor to society act. That to satiate the addiction is something infinite or unlimited, as well as what you don't want to refuse, for example, do not want to live alone and failure in life. The overall dimensions of sufficiency economy may be viewed as two sides including looking objective is the exterior look is must be comfortable four factors are sufficient, or on the side with a fairly conventionally, which coincided with the words "self-reliance" in any economy. A very subjective is a look inside the minds of the people will have enough sense not equal. Some of it isn't enough. Some are small enough. According to result of Community Culture Approach to Sustainable Development ${ }^{[3]}$ An important dimension of at least seven aspects as; i) enough for everyone no economic abandoned well, ii) mind just make to love and generosity to others, iii) the environmental sufficiency is the preserve and enhance environmental sustenance and livelihood haven, iv) the social economic, cultural and community to strong enough to the integration of a strong is able to solve different, v) sufficiency problem is learning together in practice and adapt constantly, vi) based on adequate cultural, the economy should grow out of relationships and cultural base to be stable, vii) Sufficiency security is not just flushes it until to get a sudden, do not eat the unemployed. Sufficiency Economy was solid to making good mental health. When everything was balanced is a regular and sustained. We may call sufficiency economy in other names such as economic infrastructure, economic balance, economic integration, economy moral. So, both personal and social, synchronization can be combined to achieve a substantial strengthening of the fine cultural wisdom, there is exists in both a physical and mental range.

\section{Dynamic Social Capital with Sustainable Development}

The joint activities of civic communities is creating and maintaining social relationships to pose together as a network to help each other and survive even in the crises, these movements it is known as the structure of social glue to organizations can create, relationships and norms of causing both quantity and quality. Social capital has received widespread attention in the international community. There is also a role for policymakers to solve various problems, especially poverty "social capital is the only capital that the poor and disadvantaged are". The culture of trust is encouraging members of society and unites militarily into activities of voluntary organizations for enterprises to creating growth from families of professional organizations, can be classified in three dimensions. i) First dimension: The elements of social capital consist of social network and are the relationship between the members of the network with 
social norms, which refer to the rules, values and expectations. And measures among members of social control on direct measures of reward and punishment, an indirect measure of honor and revile. The dynamic development in the first dimension can to maintain norms and networks into support of joint activities between individual and community is the social structure or formal institutions. As a condition for supporting the trust, including cooperation between the public, and can create social capital that is the social fabric. Refers to the relationship arising from the common good to achieve the goal groups or organizations, social and community, ii) Second dimension: the analysis of social capital is divided into three levels to as; micro, middle and macro. The scholars will agree to fund more social medium. It refers to the relationship between members of social organizations and the community. At the micro level, social capital refers to the close relationship of family and friends. And macro-level social capital, which refers to the relationships nationally. The dynamic development in the second dimension of social capital is equally important, all three levels. This means that any reduction in the role of social capital in the act, it can replace the function of the other. If members of the family and society began a relationship weakened, social capital loss is irreplaceable. By encouraging members to participate in the activities of the organization or can build up a relationship at the national level. iii) Third dimension: the role of social capital there are three main tasks to as; i) social capital of the groups on bonding, refers to the network of relationships within the group are already of bonding, ii) social capital group Members of bridging, refers to the network of member of a group that was bridging before, iii) members of the social capital on internal and external groups, means networking between the members of the authority and the resources are not equal and do not know each other. By linking a vertical relationship, the dynamic development in the third dimension creates social capital, though not easy. But social capital is the key to development, achieve success. According result of Social capital ${ }^{[6]}$ and A truly civil society ${ }^{[5]}$, the success of development a necessary condition of civic norms and networks between the various groups and the public sector continuous for strengthen on the basis of civil to self-management. The three important reasons are outlined: i) social beings to a relationship that connects us to one another, however, we are born with the ability of a good and evil, must learn to trust and interact and learn together, ii) can to learn and can't learn new ways, as a product of the environment is different. iii) can determine how others view us, however, we want to be part of a recognized groups. And has been satisfied with the status and the society. Based on what's more valuable, overall, though, humans are an individual, but society is built from social relationships to lead to a review, debate and controversy of policies and planning to make sense, fairness, wealth, a good citizen. And social capital as a valuable form of capital required to build a strong civil society. This is the key to development at all levels, an opportunity to share ideas, analysis, determine, planning, action, monitoring and assessment.

So the sufficiency economy into demission of social capital development will lead to the development of personal and social level of conducting a self-reliant. The dimensions of the components of development are important as:

I. Minds Dimension: the mentally strong awareness and realization that a good, independence of thought and action, creativity generosity and compromise.

II. Social and Economic Dimension: including a buddy, linking a strong network, having a careful planning in managing existing assets, having a backup plan is immune to the risks and alternatives, the value and development.

III. Technology Dimension: including the selection of what suits your needs. Known to improve the environment and reality, developed their own intellectual advancement.

IV. Cultural Dimension: an intellectual development potential and unique. Resources and the Environment dimensional including the development and use an appropriate value, ability to protect, develop and utilize it appropriately and cost-effectively with large groups and stick to a strong and sustainable.

V. Resources and Environment Dimension: including the development and use to the appropriate value.

In terms of capital development to social sustainable. Reflecting the development of a holistic approach that balances three aspects: quality, intelligence and learning, the solidarity and generosity towards each other. There are the sum of many good things, both in the accumulation and build on activities or to the development potential of the conductor and related well-being. With an emphasis on community and social of the center developed and owned initiative and participate in the decision-making process is important. The incorporation of quality benefits individuals and society. On the basis of trust a web of ties and their cultural. The crystallization of ideas looks at the problem in the same direction, the focus is on the social and development partners to encourage and support.

\section{Suggestions}

These factors are suggested to help the successful implementation of sufficiency economy: I) Mechanical factors both policy measures and the favorable including the creation of channels of participation, The need to keep evolving as an open system, there is the democracy, transparent and inspection, II) Realization of social and community issues and interests, have the ability to sense and wisdom in handling the problem of experience and learning; and III) Factor developers and development organizations, has been an active in promoting stimulus, awareness permitting and development process. 


\section{REFERENCES}

[1] Prawas Vasri. [2006]. The sufficiency economy philosophy of His Majesty the King of Thailand social development. Bangkok: Chulalongkorn University Publisher.

[2] Chathip Natsupa and Teams. [1998]. Economic Community Farmers .Bangkok: Publisher of Vetitas.

[3] Bamrung Bunpranya .[2005]. Community culture approach to sustainable development. Bangkok: Development Institute Community Organizations.

[4] Pornchai Jedaman. [2013]. Human resource: Management using with your hard and brain. Bangkok: Sudprisanbuilder.

[5] Cox, Eva. [1995]. A truly civil society. Sydney: ABC Books.

[6] Halpern, David. [2005]. Social capital. Cambridge: Polity Press.
[7] Curry, Robert, Jr. \& Sura, Kanchana. [2007]. Human resource development (HRD) theory and Thailand's sufficiency economy concept and its "OTOP" program. Journal of Third World Studies, XXIV,(2), 85-94.

[8] Unger, Danny. [2009]. Sufficiency economy and the bourgeois virtues. Asian Affairs: An American Review, 36(3), 139-156.

[9] Boondao. R. [2011]. Spatial decision support system for provincial development by the use of the principles of self-sufficiency economy. International Journal of Geoinformatics, 7(3), 35-43.

[10] Noy, Darren. [2011]. Thailand's sufficiency economy: Origins and comparisons with other systems of religious economics. Social compass, 58(4), 593-610.

[11] Rossi, Amalia. [2012]. Turning red rural landscapes yellow? sufficiency economy and royal projects in the hills of Nan Province, Northern Thailand. Austrian Journal of South-East Asian Studies, 5(2), 275-291. 